\title{
THE PREVENTION OF HEAD INJURIES
}

\author{
WalPole Lewin, M.S.(Lond.), F.R.C.S.(Eng.) \\ Department of Neurological Surgery and Neurology, Addenbrooke's Hospital, Cambridge
}

Prevention suggests infectious disease and one way by which the importance of accidents as a cause of death may be highlighted is to compare the changing relationship over the years between the mortality rates of accidents and infectious diseases. Gissane ( 1962 ) pointed out that in 1946 deaths in England and Wales due to infectious diseases were twice those due to accidents but by I 956 the roles were reversed, deaths from infectious diseases then being half those due to accidents. There are many reasons for this but accident deaths have risen steadily and in 1960 totalled 17,720, of which road accidents were responsible for $40 \%$; whereas deaths from infectious diseases in that year had fallen to 5,500 . No wonder that he refers to accidents as the major epidemiological revolution that has taken place in this country.

The reason for concentrating on head injuries and their prevention lies partly in the rôle they play in the mortality rate from accidents. Thus $60 \%$ of all road accident deaths are associated with head injury. Of fatal motor vehicle accidents over half are due to head injury and the figure among motor cyclists is even higher, between 80 to $90 \%$. In accidents as a whole, at least one-third of all road accidents requiring admission to hospital do so on grounds of head injury. It is immediately clear therefore, that any measures which can prevent a head injury occurring or which will mitigate its effects can have the most profound influence in reducing the accident mortality as a whole.

What groups of people are most liable to head injury? Of 1,000 consecutive head injuries admitted to hospital (Table I) it will be seen that roughly two-thirds came from road accidents. The high incidence of pedal cycle accidents betrays a University city, but it is particularly important to note the high number of motor cycle accidents, accounting for nearly a quarter of the total. Considering the small number of motor cycles on the road compared with cars, and the greater numbers of pedal cyclists and pedestrians, the

A paper read to the Harveian Society of London, November $21,1962$.
TABle I

Accident Details in I , 000 Consecutive Head Injuries (Direct AdMISSION)

\begin{tabular}{|c|c|c|c|}
\hline Type & Recovered & Died & Total \\
\hline $\begin{array}{lll}\text { Car } . . & . & \\
\text { Motor-cycle } & . . & \\
\text { Push cycle } & \ldots & \text {. } \\
\text { Pedestrian } & \ldots & \text {. }\end{array}$ & $\begin{array}{l}116 \\
208 \\
219 \\
142\end{array}$ & $\begin{array}{r}9 \\
16 \\
14 \\
21\end{array}$ & $\begin{array}{l}125 \\
224 \\
233 \\
163\end{array}$ \\
\hline $\begin{array}{l}\text { All road accidents: } \\
\text { At work .. } \\
\text { At home } . . \\
\text { At play } . \\
\text { Other (assault, etc. }\end{array}$ & $\begin{array}{r}685 \\
45 \\
58 \\
83 \\
58\end{array}$ & $\begin{array}{r}60 \\
6 \\
4 \\
0 \\
1\end{array}$ & $\begin{array}{r}745 \\
51 \\
62 \\
83 \\
59\end{array}$ \\
\hline & 929 & 71 & $1, \infty 00$ \\
\hline
\end{tabular}

particular risk of the motor cyclist is immediately apparent.

Preventive measures for head injuries have been known for many years from the hazards at home and at sport as well as those of work and on the roads. Our forefathers, for example, were well aware of the need to protect the head when hunting. Ferrarius' book on pædiatrics in 1577 includes a reference to probably the first crash helmet for infants. He says ... 'beginning in the early stage I recommend that everyday should be put on the child's head a sort of round, smooth fillet made of linen rag of the skin of a kid and filled with cotton wool like a King's crown divided into four parts. .. ' In industry the miner's helmet is well known. Racing drivers have had specifically designed crash helmets since I92I.

In this paper our observations are concentrated on two particular groups, the motor cyclist and the motor vehicle occupant. It is of course clear that the various measures to be taken should combine to prevent the incident occurring altogether. As far as road accidents are concerned, there is a rich field for enquiry into the mental and physical standards of road users, the state of the vehicles, the condition of the roads, the effect of alcohol and many other matters. In all these the doctor is intimately concerned, but at the moment we are considering those specific measures which may prevent some head injuries and lessen the effects of others. 


\section{The motor-cyclist}

The particular hazard of head injury run by the motor-cyclist has been described many times before (Cairns, 194I; Starks, 1952; Lewin and Kennedy, 1956). He rides relatively unprotected and however skilful a rider is not proof against skids and unexpected hazards. It has been estimated that the risk of a motor-cycle accident is 17 times that of a motor vehicle for every mile travelled. His place in the head-injury statistics already instanced reinforces this view. Indeed during to-day a further four motor-cyclists will have lost their lives on the roads of this country.

The value of crash helmets was recognized in the early days of the last war and many will be familiar with the figures showing the improvement in head injury fatalities following the compulsory wearing of crash helmets by the Army in 194I. Despite a good deal of investigation on the value of helmets which was continued after the war surprisingly little enthusiasm was shown by the public to protect itself. In 1953, however, the Metropolitan police adopted the 'corker' helmet and this resulted in some $10^{\circ}{ }_{0}^{\prime}$ of the public following suit. More rapid progress was then made by a combination of example and publicity campaigns so that by $195^{8}$ a police survey suggested that some $42^{\circ} / 0$ of motor cyclists were wearing crash helmets. Disappointingly little progress has been made since. It has been suggested that the overall figure now stands at $60 \%$ or more. This may well be so over the main trunk roads leading out of London where motor-cyclists are frequently equipped for a long journey. Over the country as a whole, however, the figure is probably not more than $50 \%$. It is more salutary to note that 2 I years after the value of a crash helmet was demonstrated, half the young people riding motor-cycles in our country still do so unprotected.

Before asking what more, if anything, should be done in this field it is pertinent for doctors to enquire whether it is known what a helmet will do, what is the evidence of its effectiveness, and thirdly if sufficient is known of the type of helmet which should be recommended. An efficient crash helmet will spread the force of the blow and reduce the degree of concussion, and in less severe blows will prevent a concussion altogether. A properly made helmet will reduce significantly the likelihood of penetrating wounds of the skull and brain with all their particular complications. The figures suggest that a crash helmet will reduce the risk of head injury by at least $30 \%$ and the risk of death by $50 \%$ (Lewin and Kennedy, 1956; Moore 1962). On two occasions now we have conducted surveys on patients admitted with head injury to judge the effectiveness of a
TABLE 2

Head Injuries in Motor-cyclists (555 CASEs)

\begin{tabular}{|c|c|c|c|}
\hline Years & Number & $\begin{array}{l}\text { Wearing } \\
\text { Crash } \\
\text { Helmet }\end{array}$ & $\begin{array}{c}\text { No Crash } \\
\text { Helmet }\end{array}$ \\
\hline $1949-52$ & 303 (27 deaths) & & 302 (27 death \\
\hline 1953 & II2(11 & 3 & 109 (II \\
\hline 1954 & $140(10 \quad, \quad)$ & (3 deaths) & $117(7$ \\
\hline
\end{tabular}

TABLE 3

Head INJURIES IN Motor-CyClists, 1962

\begin{tabular}{|c|c|c|c|c|}
\hline & $\begin{array}{c}\text { P.T.A. } \\
-24 \\
\text { hours }\end{array}$ & $\begin{array}{l}\text { P.T.A. } \\
+24 \\
\text { hours }\end{array}$ & Died & $\begin{array}{r}\vec{\omega} \\
\text { Tota } \\
\overrightarrow{8}\end{array}$ \\
\hline $\begin{array}{l}\text { Wearing crash hel- } \\
\text { met } \quad .\end{array}$ & 30 & 4 & I & \\
\hline $\begin{array}{l}\text { Not wearing crash } \\
\text { helmet }\end{array}$ & 24 & 3 & 5 & 32 \\
\hline \multirow[t]{2}{*}{$\begin{array}{ll}\text { Unknown } & \ldots\end{array}$} & $\begin{array}{r}24 \\
2\end{array}$ & $\begin{array}{l}3 \\
\mathbf{I}\end{array}$ & $\stackrel{5}{-}$ & \\
\hline & 56 & 8 & 6 & \\
\hline
\end{tabular}

crash helmet. In the first survey in 1954, wher helmets were first being used to a significa extent, there was a definite trend suggesting the that a helmet did reduce the risk of death amorig motor-cyclists. (Table 2). Of the three deatho of motor-cyclists wearing crash helmets in thit series, in one there was a witness's account कhat the helmet flew off before the patient struck ho head; in the second the cause of death was main the effects of accompanying jaw and chest injurie ; and in the third where an efficient helmet was worn there was a head-on crash into a brick wal at 75 m.p.h. This latter case is worth emphasizir when criticism is advanced after someone has died even though he was wearing a helmet. helmet can guarantee protection against a ferocious blow. In 1962 a further survey was completed of 70 motor cyclists admitted consecutively hospital with head injury (Table 3 ). It will seen that among the patients wearing craş helmets there was only one death, and here agag there were special circumstances. This patient was older than most at $5^{8}$ years, and a diabetio. He received a fracture of the skull in the right frontal region but was talking on admission th hospital. Later he developed broncho-pneumonfig with heart failure and subsequent renal failure By contrast there were five deaths among th patients not wearing crash helmets, all due to the severity of the head injury. This and other evidence from several sources seems to make the issue clear cut: that a proper helmet will lesse not only the severity of the injury but reduce the risk of loss of life.

Is enough known of the design, type and shan 
of a helmet that may be recommended with confidence? Work on this subject has continued at the Road Research Laboratory and at the Air Force Institute of Aviation Medicine, Farnborough (Rawlings, 1956), for many years. All this has recently culminated in recommendations for a new British standard for helmets which has taken into account the present state of our knowledge on helmets both in the research and clinical field.

Finally what is one doing to persuade motorcyclists to wear crash helmets? For some years now, under the ægis of the British Medical Association, steady pressure has been put onto the Ministry of Transport to make the wearing of crash helmets compulsory. This view has been recently reinforced and it will be known that the new Road Traffic Bill includes a provision which will allow the Minister to enforce the compulsory wearing of helmets if this is found to be necessary. There is a natural and proper aversion to compulsion if persuasion will be as effective and a further publicity campaign is promised to try and lift the percentage of motor cyclists wearing helmets to such a degree as to make a compulsory order unnecessary. The medical profession will undoubtedly support such a campaign. It is doubtful, however, whether it will meet with the degree of success that is necessary and in that event a compulsory order will be needed. Let us hope this will not come too late.

\section{The Motorist}

The motor-cyclist and his crash helmet have received a good deal of publicity over the last 1o years or so but until recently little has been done for the motor vehicle occupant. In the early years little was known of the type of injury he sustained and his particular risk, if any, of head injury. In fact, over half the deaths of motor vehicle occupants are due to head injury, and head injury accounts for $60 \%$ of all injuries in cars. (Rutley and Cook, 1960). There is also evidence accumulating that over the last few years the proportion of fatal car accidents is increasing. Whether this is due to increased speed, to the more fragile design of many newer and smaller cars, or other factors is not for the present discussion but clearly the time has come when consideration has to be given to the prevention of injury in motor vehicles. In the last three years in conjunction with the Road Research Laboratory the special problem of the head injury in motor vehicles has been studied, based on a consecutive series of 525 motor car drivers and occupants admitted to hospital with head injury (Lewin and Moore, 1964). Frontal and facial regions accounted for the majority of the injuries. Experimental evidence had previously suggested that the head tends to move upwards and forwards in motor accidents and this accounts for the high proportion of facial injuries.

The limitation of protective headgear in such circumstances is immediately seen. A head cap will do little to protect against a quarter of the injuries which are predominantly facial. An effective cap like a motor-cyclist's crash helmet, to give worth-while protection against the true head injury, would not be accepted for general use. Undoubtedly, however, attempts to develop a suitable cap for the motorist should be explored further, and indeed work is now proceeding to discover whether with modern materials a cap could be designed to give not only the extra coverage but sufficient energy absorption to provide some measure of protection and also reduce the risk of penetrating injury.

A more immediate solution and one which can be aimed at preventing injuries other than to the head as well, is to pad not the head but the car interior. It seems clear that if one padded the inside of cars with the same care as one packages eggs, a significant step forward would be made. It is equally important to design cars so that all inside projections are removed, as these are frequent causes of compound head injuries. more concerted effort is required to impress on car manufacturers the need to pay attention to these points in future car designs.

A third way by which the problem may be tackled is to provide a safety harness in cars. This would reduce the deceleration concussion on the head and lessen the risks of impact. However, the full implications of the safety harness are not yet known and it is likely that, as regards the prevention of head injury at least, the answer may be a combination of at least these three approaches.

\section{Conclusions}

In this paper the emphasis has been on the mortality from head injury since this is clearly the matter of immediate moment and the one which the public can most easily appreciate. However, in medical circles we are also only too fully aware of the considerable disability that may result from a non-fatal head injury. The effects of a severe concussion with its impairment of memory and concentration can render an executive incapable of his job; or the effects of epilepsy and hemiparesis may make it impossible for a labourer to get back to open employment. Measures, therefore,' that prevent these complications or lessen their effects are important not only to the individual but to the economy of the country as a whole. 
One of the modern medical fashions is to publicize the risks of doing practically anything, whether it is riding a motor cycle, eating a lollipop or stroking the cat. However, few would question the doctor's duty nowadays to highlight the need to prevent accidents, not only because of their numbers but because others become innocently involved in their effects. The solution to the accident problem is no easy one, and is likely to have several facets. Moreover the prevention of one injury cannot be fully considered to the exclusion of injuries to other parts of the body. $\frac{a}{z}$ The reasons for concentrating on head injuries, $\mathbb{\infty}$ however, were given at the beginning of this ${ }_{C}$ paper; and also because here at least is one injury where relatively simple preventive measures are $\stackrel{S}{\rightarrow}$ available. Every effort should be made to ensure their adoption.

My thanks are due to the Editors of the Proceedings of the Royal Society of Medicine for permission to reproduce Table I, and the British Medical Fournal for permission to reproduce Table 2.

\section{REFERENCES}

CaIRns, H. (1941): Head Injuries in Motor Cyclists, Brit. med. F., ii, 465.

FRRRARIUS (1 577): 'De Arte medical Infantium', Verona.

GIsSANE, W. (1962): 'Accidental Injuries and their Prevention'. Report to the Accident Services Review Committee, Great Britain and Northern Ireland.

Lewin, W., and KenNedy, W. F. C. (1956): Motor Cyclists, Crash Helmets and Head Injuries, Brit. med. F., i, 1253.

, and MOoRE, R. L. (1964): 'Prevention of Head Injury in Motorists, with special reference to Head Caps'. In press.

MOoRE, R. L. (1962): How Crash Helmets Save Life, New Scientist, 15, 288.

RAwlings, J. S. P. (I956): Design of Crash Helmets, Lancet, ii, 7 I9.

RUTLEY, K. S., and Cook, J. A. (1960): 'A Survey of the Incidence of Head Injuries to the Occupants of Cars and ? Commercial Vehicles', Road Research Lab. Note 3773.

Starks, H. S. H. (1952): Road Research Lab. Note 1746. 